\title{
Developmental Changes in the Enzymatic Capacity for Reduction and Oxidation of $\alpha$-Ketoadipate in Rat Liver, Heart, Kidney, and Brain
}

\author{
TOMIO SUDA, J. C. ROBINSON, AND THORSTEN A. FJELLSTEDT ${ }^{(28)}$ \\ Section on Developmental Enzymology, Laboratory of Biomedical Sciences, National Institute of Child Health \\ and Human Development, National Institutes of Health, Bethesda, Maryland, USA
}

\section{Summary}

$\alpha$-Ketoadipate, an intermediate common to lysine and tryptophan metabolism, is a substrate for both $\alpha$-ketoadipate reductase $(\alpha-K A R)$ and $\alpha$-ketoadipate dehydrogenase ( $\alpha$-KADH). A comparison was made of the activities of these two enzymes in liver, heart, kidney, and brain of rats during the period from 5 days before birth to 56 days after birth. In general, both enzymes increased in activity during development in all tissues tested; however, different patterns of increase were observed (Figs. 1 and 2).

The ratio of $\alpha \cdot K A D H$ to $\alpha-K A R$ (on the basis of activity/g tissue) did not change significantly in liver until day 10 and then increased 6.6-fold (from 0.08 to 0.53 ) in the period from day 10 to day 28. For other tissues the ratios increased 5.5 -fold in hearts (from 0.2 to 1.1 ), 12-fold in kidney (from 0.2 to 2.4), and 5.3 -fold in brain (from 0.3 to 1.6 ) during the period from day -5 to day 56.

These results suggest that $\alpha-K A R$ has a major role in the metabolism of lysine and tryptophan during development.

\section{Speculation}

In the late fetal stage, the metabolism of $\alpha$-ketoadipate depends more on reduction to $\alpha$-hydroxyadipate than on oxidation to glutaryl-CoA; as development progresses there is a shift to a greater dependence on the oxidative reaction. If an analogous pattern is present in human development, then $\alpha$-ketoadipate metabolism in the developing individual with $\alpha$-ketoadipic aciduria would remain similar to that of the fetal period, and this might explain the abnormal accumulation not only of $\alpha$ ketoadipate but also of $\alpha$-hydroxyadipate found in these individuals.

The degradative route for lysine in mammals has been shown to join that of tryptophan at $\alpha$-ketoadipate. $\alpha$-Ketoadipate is believed then to undergo an oxidative decarboxylation to yield glutaryl-CoA and $\mathrm{CO}_{2}(2,13,14)$. The enzyme catalyzing this decarboxylation is only tentatively referred to as $\alpha$-ketoadipate dehydrogenase ( $\alpha$-KADH) because a highly purified $\alpha$-ketoglutarate dehydrogenase complex has also been reported to catalyze this reaction $(7,9,14)$. We have recently described the purification and characterization (23), as well as the subcellular localization and tissue distribution (24), of an enzyme designated $\alpha$-ketoadipate reductase ( $\alpha$-KAR), which specifically mediates the NADH-dependent reduction of $\alpha$-ketoadipate to $\alpha$ hydroxyadipate.

Recent papers have described several human metabolic defects that involve the degradation of $\alpha$-ketoadipate: $\alpha$-ketoadipic aciduria $(18,25,26)$, glutaric aciduria $(5,6,22)$, and glutaric aciduria type II (19). An individual with $\alpha$-ketoadipic aciduria, apparently resulting from a defect in the decarboxylation of $\alpha$ ketoadipate, was reported to have increased urinary excretion not only of $\alpha$-ketoadipate but also of $\alpha$-hydroxyadipate (17, 25 ); these findings suggest the rossibility of an alternate route of $\alpha$-ketoadipate degradation (Scneme 1).

We reported previously that $\alpha$-KAR has a dominant metabolic role in tissues that have a relatively low density of mitochondria and that $\alpha-\mathrm{KADH}$ has a dominant metabolic role in tissues that have a relatively high density of mitochondria (24). It would be expected, therefore, that the developmental processes occurring in utero, at parturition, and thereafter would influence the relative activities of these enzymes and consequently control the major degradative route of $\alpha$-ketoadipate. This report describes a developmental study of $\alpha$-KAR and $\alpha$ $\mathrm{KADH}$ in several tissues of the rat beginning at 5 days preterm and continuing through the 8 th postpartum week. No data were previously available concerning the relative activities of $\alpha$-KAR and $\alpha-\mathrm{KADH}$ during this critical developmental period.

\section{MATERIALS AND METHODS}

\section{ANIMALS}

Sprague-Dawley rats were obtained from Zivic-Miller Laboratories, Inc., Allison Park, PA. Pregnant rats, lactating rats, and young rats had unlimited access to water and food before they were killed.

\section{PREPARATION OF ENZYMES}

Rats were decapitated and bled thoroughly, and the organs under study were quickly removed. Because of the small size of some of the fetal and early postnatal organs it was necessary to combine specific organs from several fetuses and pups for a given enzyme preparation. For studies using animals that were 5 days preterm, 3 days preterm, 1 day preterm, and 1 day postpartum, each enzyme preparation was derived from the combination of the respective organs from an entire litter; for studies using animals that were 5 days, 10 days, and 17 days postpartum, each enzyme preparation was derived from a combination of the respective organs from five or six suckling pups for studies using animals that were 28 days and 56 days postpartum, each enzyme preparation was derived from the combination of the respective organs of one male and one female rat.

All procedures were carried out at $0-4^{\circ}$. Each tissue sample was blotted with filter paper, minced with scissors, suspended in 9 vol $0.25 \mathrm{M}$ sucrose solution (adjusted to $\mathrm{pH} 7.0$ with $\mathrm{KOH}$ ), 
and homogenized in a Teflon homogenizer. Half of each homogenate was centrifuged at $105,000 \times g$ for $1 \mathrm{hr}$, and the supernatant fraction was used for the $\alpha-$ KAR assay. The remaining homogenate was sonicated for $2 \mathrm{~min}$ with a Raytheon magnetostrictive oscillator, model DF 101, and used for the $\alpha$ $\mathrm{KADH}$ assay.

\section{ASSAY}

$\alpha$-Ketoadipate reductase activity of each supernatant fraction was determined at $37^{\circ}$ by following the oxidation of $0.1 \mathrm{nM}$ $\mathrm{NADH}$ at $340 \mathrm{~nm}$ in the presence of $10 \mathrm{mM} \alpha$-ketoadipate in $0.05 \mathrm{M}$ maleate buffer, $\mathrm{pH} 6.3$. The total volume of the reaction mixture was $0.6 \mathrm{ml} . \alpha$-Ketoadipate was omitted from the control cuvette.

$\alpha$-Ketoadipate dehydrogenase was assayed by measuring the formation of ${ }^{14} \mathrm{CO}_{2}$ with $\alpha-\left[1-{ }^{14} \mathrm{C}\right]$ ketoadipate as substrate (27). $\alpha-\left[1-{ }^{14} \mathrm{C}\right]$ Ketoadipate was prepared as described previously (23). The reaction mixture had a final volume of $1.0 \mathrm{ml}$ and contained $5 \mathrm{mM} \alpha-\left[1-^{14} \mathrm{C}\right]$ ketoadipate $(0.12 \mu \mathrm{Ci}), 0.8 \mathrm{mM}$ NAD, $0.8 \mathrm{mM}$ CoA, $0.8 \mathrm{mM}$ thiamine pyrophosphate, $0.8 \mathrm{mM}$ $\mathrm{CaCl}_{2}, 0.8 \mathrm{mM} \mathrm{Na}_{2} \mathrm{CO}_{3}, 5 \mathrm{mM}$ cysteine, and $75 \mathrm{mM}$ potassium phosphate buffer, $\mathrm{pH}$ 7.2. Calcium ion was reported to stimulate $\alpha$-ketoglutarate dehydrogenase more strongly than $\mathrm{Mg}^{2+}(9)$. The activity of $\alpha$-ketoadipate dehydrogenase was also found to increase by $30-40 \%$ when $\mathrm{Ca}^{2+}$ was used instead of $\mathrm{Mg}^{2+}$. Enzyme activities of both $\alpha-\mathrm{KADH}$ and $\alpha-\mathrm{KAR}$ were expressed in terms of units/g tissue and in units/g protein. A unit is that amount of enzyme transforming $1 \mu \mathrm{mol}$ substrate $/ \mathrm{min}$ at $37^{\circ}$.

Protein content was determined by the method of Lowry et al. (12).

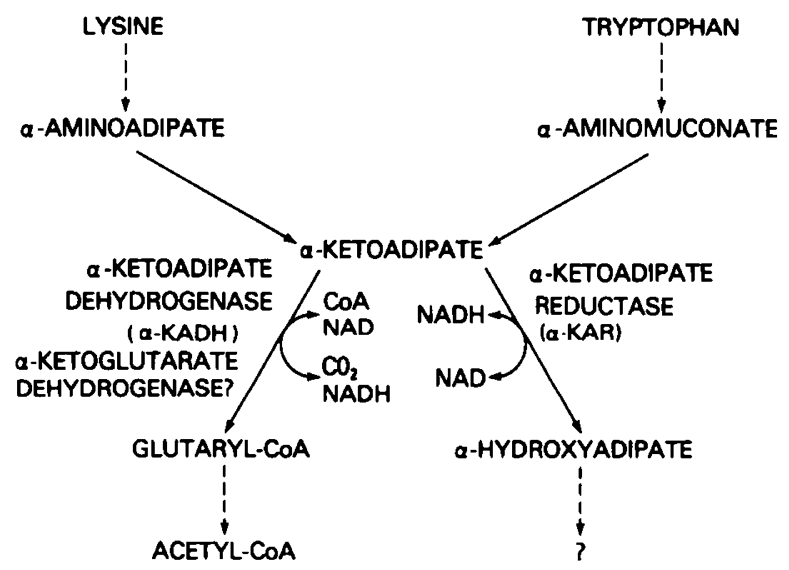

Scheme 1. Steps in $\alpha$-ketoadipate metabolism.

\section{RESULTS}

As can be seen in Figure $1, A$ and $B$, there was a general but variable trend of increases in activity for both $\alpha$-KAR and $\alpha$ KADH during development in all tissues tested; however, the patterns of activity changes for these two enzymes were quite different. $\alpha$-KAR underwent smaller increases during development than did $\alpha$-KADH (Fig. 1). Kidney, heart, and liver $\alpha$ KAR increased from 1.5 to 2.5 times in activity during the period from day -1 to day 17 (significant at $\alpha=0.01$; Fig. $1 A$ ), whereas brain $\alpha$-KAR showed no significant change in activity until day $1(\alpha=0.10)$ and then increased 3-fold by day 28 (significant at $\alpha=0.01$ ). The activities of $\alpha$-KADH in heart and kidney showed a continuous rise, which resulted in 8-fold and 29 -fold increases, respectively, during the period from day -5 to day 28 (significant at $\alpha=0.01$; Fig. $1 B$ ). Brain $\alpha-\mathrm{KADH}$ increased 7-fold in this period (significant at $\alpha=0.01$ ). The activity of $\alpha-\mathrm{KADH}$ in liver did not change significantly until day $10(\alpha=0.10)$, after which it increased 7-fold reaching a plateau at day 28 (significant at $\alpha<0.001$ ).

In order to eliminate the difficulty in comparing enzyme activities found in two different preparations (homogenate versus supernatant fluid), Figure 2 provides the ratio of the two activities (on the basis of activity/g tissue) and clearly demonstrates the changes during the developmental period. These ratios in liver showed no significant change until day 10 and then increased 6.6-fold (from 0.08 to 0.53 ) in the period from day 10 to day 28 . In each of the other tissues, the ratios increased 5.5fold in heart (from 0.2 to 1.1 ), 12-fold in kidney (from 0.2 to 2.4 ), and 5.3-fold in brain (from 0.3 to 1.6 ) in the period from day -5 to day 56 .

\section{DISCUSSION}

It has been shown that $\alpha$-KAR is associated principally with the particulate-free supernatant fraction of rat liver (24). The use of this fraction allows a valid estimation of cellular activity and, in addition, improves sensitivity to changes in activity. A valid estimate of cellular activity of $\alpha$-KADH was best obtained using a crude homogenate of each organ (24).

Although it has not been established whether $\alpha-\mathrm{KADH}$ and $\alpha$-ketoglutarate dehydrogenase activities are properties of the same enzyme or of different enzymes, purified $\alpha$-ketoglutarate dehydrogenase complex has been shown to be active with $\alpha$ ketoadipate $(7,9,14)$. It is, therefore, of concern that our studies report increasing activity of $\alpha-\mathrm{KADH}$ during development, whereas the studies of others on $\alpha$-ketoglutarate dehydrogenase, also in rat liver, reported almost constant activity during a similar time period (8). It should be noted that this reported

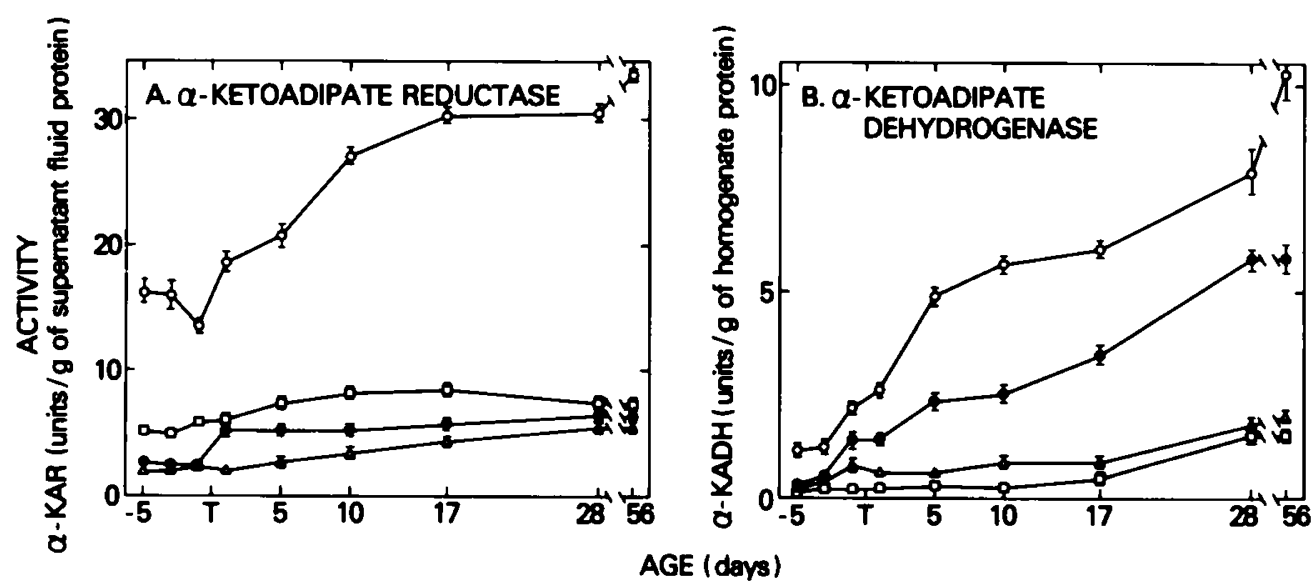

Fig. 1. Activities of $(A) \alpha-\mathrm{KAR}$ and $(B) \alpha-\mathrm{KADH}$ as a function of age. Enzymes in heart $(O)$, kidney $(\bullet)$, liver $(\square)$, and brain $(\triangle)$. T: term. Each point represents the mean of four to six assays on two to three samples of tissue collection; the vertical bar shows \pm SEM when large enough to record. For details of the method for tissue collection see Materials and Methods. 


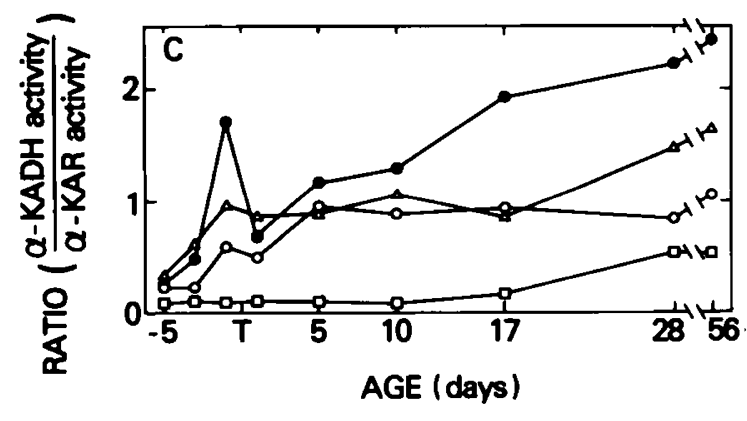

Fig. 2. The ratio of $\alpha-\mathrm{KAR}$ to $\alpha-\mathrm{KADH}$ as a function of age based on activity/g tissue. Ratios in heart $(O)$, in kidney $(\bullet)$, in liver $(\square)$, and in brain $(\Delta)$.

activity was extremely low and that the spectrophotometric assay based on NAD reduction is inappropriate for the assay of this enzyme in crude preparations $(10,20)$; in these studies $(8)$ it was found that the $\alpha$-KADH activities were unexpectedly low (about $0.3 \mathrm{nmol} / \mathrm{min} / \mathrm{mg}$ mitochondrial protein). The presence of compounds that caused reoxidation of NADH in crude preparations results in artificially low values $(10,20)$. The method using ferricyanide as the electron acceptor (19) is applicable for crude preparations, including the homogenate ( 7 , $20)$, even though $\alpha-\mathrm{KADH}$ activities assayed by this method have been reported to be only one-seventh to one-eighth of the activity assayed by measuring NAD reduction in fractions that were partially purified or were homogenous $(7,9)$. This is explained by the fact that the ferricyanide assay method measures the dehydrogenase reaction of the complex, whereas the NAD assay method measures the overall reaction. We have reported an $\alpha-\mathrm{KADH}$ activity in rat liver mitochondria of 10.1 $\mathrm{nmol} / \mathrm{min} / \mathrm{mg}$ protein using the ferricyanide method (24). By applying a factor of 7 to our results (the difference between the dehydrogenase assay and the overall assay), a favorable comparison is achieved between our results and those of others using the overall assay procedure in rat liver mitochondria (21). These activities are considerably greater than the activities reported using the aforementioned inappropriate NAD assay method.

In previous reports of the tissue distribution of $\alpha$-KAR and $\alpha-\mathrm{KADH}$, it was shown that heart, kidney, liver, and brain have the highest activities for both of these enzymes (24). Since liver is by far the largest of the organs under study, developmental changes that occur in enzyme activities of this organ must be considered to be of prime importance to the overall metabolism of the whole animal. A very low amount of $\alpha-\mathrm{KADH}$ activity was found until day 10; however, this increased substantially after weaning. One explanation of this finding could be related to the high fat and low carbohydrate content of milk (3) and the resultant higher hepatic lipid oxidation rates $(1,4)$, which require $\mathrm{CoA}$. This situation could possibly lead to the repression or inhibition of $\alpha$-KADH. That the $\alpha$-KAR activities in liver were over 10 times higher than the $\alpha-\mathrm{KADH}$ activities throughout the period from day -5 to day 10 suggests that formation of $\alpha$-hydroxyadipate is the major route of $\alpha$-ketoadipate degradation in liver during this period. During this period the conversion of $\alpha$-ketoadipate to glutaryl-CoA may be carried out mainly in heart and kidney.

We reported previously that in subcellular fractions of rat liver $\alpha$-KADH is principally associated with the mitochondria. Comparison of $\alpha$-KAR with $\alpha$-KADH showed that $\alpha$-KAR is higher in activity in tissues that have relatively low density of mitochondria, such as skeletal muscle, and that $\alpha-\mathrm{KADH}$ is greater in tissue that have relatively high density of mitochondria, such as kidney (24). The mitochondrial density in rat liver increases during development $(11,16)$. Embryonic tissues are highly dependent on anaerobic glycolysis for energy (15). The aerobic respiratory metabolic function of liver mitochondria increases during development (15), whereas the accompanying anaerobic metabolism decreases during this time. In the present work, the ratio of $\alpha$-KADH activities to $\alpha$-KAR activities in the tissues tested increased during development. These findings are in agreement with the concept that as development progresses there is a shift to a greater dependence on oxidative metabolism.

\section{CONCLUSION}

The activities of both $\alpha$-KAR and $\alpha$-KADH increased in liver, heart, kidney, and brain of rats during the period from day -5 to day 56 .

The ratios of $\alpha$-KADH to $\alpha$-KAR (on the basis of activity/g tissue) in liver showed no significant change until day 10 and then increased 6.6-fold in the period from day 10 to day 28 . This ratio was found to increase 5.5-fold in heart, 12-fold in kidney, and 5.3-fold in brain during the period from day -5 to day 56. Taking organ weights into account, these results suggest that $\alpha$-KAR may have a dominant role in $\alpha$-ketoadipate metabolism during the late fetal and early postnatal stages. However, as development progresses, $\alpha$-KADH makes an increasingly significant contribution to the metabolism of $\alpha$-ketoadipate.

\section{REFERENCES AND NOTES}

1. Bailey, E., and Lockwood, E. A.: Some aspects of fatty acid oxidation and ketone body formation and utilization during development of the rat. Enzyme, 15: 239 (1973).

2. Borsook, H., Deasy, C. L., Haagen-Smit, A. J., Keighley, G., and Lowy, P. $H$.: The degradation of $\alpha$-aminoadipic acid in guinea pig liver homogenate. J. Biol. Chem., 176: 1395 (1948).

3. Dymsza, H. A., Czajka, D. M., and Miller, S. A.: Influence of artificial diet on weight gain and body composition of the neonatal rat. J. Nutr., 84: 100 (1964).

4. Foster, P. C., and Bailey, E.: Changes in hepatic fatty acid degradation and blood lipid and ketone body content during development of the rat. Enzyme, 21: 397 (1976).

5. Goodman, S. I., and Kohlhoff, J. G.: Glutaric aciduria: Inherited deficiency of glutaryl-CoA dehydrogenase activity. Biochem. Med., 13: 138 (1975).

6. Goodman, S. I., Markey, S. P., Moe, P. G., Miles, B. S., and Teng, C. C.: Glutaric aciduria: A new disorder of amino acid metabolism. Biochem. Med., 12: 12 (1975)

7. Hirashima, M., Hayakawa, T., and Koike, M.: Mammalian $\alpha$-keto acid dehydrogenase complexes. II. J. Biol. Chem., 242: 902 (1967)

8. Hommes, F. A., Haan, G. L., and Richthers, A. R.: The development of some Krebs cycle enzymes in rat liver mitochondria. Biol. Neonat., 17: 15 (1971).

9. Kanzaki, T., Hayakawa, T., Hamada, M., Fukuyashi, Y., and Koike, M.: Mammalian $\alpha$-keto acid dehydrogenase complexes. IV. J. Biol. Chem. 244: 1183 (1969).

10. Kaufman, S.: $\alpha$-Ketoglutaric dehydrogenase system and phosphorylating enzyme from heart muscle. Methods Enzymol., 1: 714 (1955).

11. Lang, C. A., and Herbener, G. H.: Quantitative comparison of the mitochondrial populations in the livers of newborn and weanling rats. Develop. Biol., 29: 176 (1972).

12. Lowry, O. H., Rosebrough, N. J., Farr, A. L., and Randall, R. J.: Protein measurement with the Folin phenol reagent. J. Biol. Chem., 193: 265 (1951).

13. Nishizuka, Y., Ichiyama, A., Choloson, R. K., and Hayaishi, O.: Studies on the metabolism of the benzene ring of tryptophan in mammalian tissue. J. Biol. Chem., 240: 733 (1965).

14. Nishizuka, Y., Ichiyama, A., and Hayaishi, O.: Metabolism of the benzene ring of tryptophan (mammals). V. $\alpha$-Ketoadipate dehydrogenase. Methods Enzymol., 17a: 487 (1970).

15. Norris, J. L., Blanchard, J., and Povolny, C.: Regeneration of rat liver at different ages. Arch. Pathol., 34: 208 (1942).

16. Ontko, J. A.: Genesis of liver mitochondria in neonatal rat. Life Sci., 5: 817 (1966).

17. Przyrembel, H., Bachmann, D., Lombeck, I., Becker, K., Wendel, U., Wadman, S. K., and Bremer, H. J.: Alpha-ketoadipic aciduria, a new inborn error of lysine metabolism: Biochemical studies. Clin. Chim. Acta 58: 257 (1975).

18. Przyrembel, H., Wendel, U., Becker, K., Bremer, H. J., Bruinvis, L. Ketting, D., and Wadman, S. K.: Glutaric aciduria type II: Report on a previously undescribed metabolic disorder. Clin. Chim. Acta, 66: 227 (1976).

19. Reed, L. J., and Willms, C. R.: Purification and resolution of the pyruvate dehydrogenase complex II. B. Pyruvate decarboxylase. Methods Enzymol., 9: 258 (1966).

20. Sanadi, D. R.: $\alpha$-Ketoglutarate dehydrogenase from pig heart. Methods Enzymol., 13: 52 (1969).

21. Schnaitman, C., and Greenawalt, J. W.: Enzymatic properties of the inner and outer membranes of rat liver mitochondria. J. Cell. Biol., 38: 158 (1968). 
22. Stokke, O., Goodman, S. I., and Thompson, J. A.: Glutaric aciduria: Presence of glutaconic and $\beta$-hydroxyglutaric acids in urine. Biochem. Med., 12: 386 (1975).

23. Suda, T., Robinson, J. C., and Fjellstedt, T. A.: Purification and properties of $\alpha$-ketoadipate reductase, a newly discovered enzyme from human placenta. Arch. Biochem. Biophys., 176: 610 (1976).

24. Suda, T., Robinson, J. C., and Fjellstedt, T. A.: Subcellular localization and tissue distribution of $\alpha$-ketoadipate reduction and oxidation in the rat. Biochem. Biophys. Res. Commun., 77: 586 (1977).

25. Wendel, U., Rüdiger, H. W., Przyrembel, H., and Bremer, H. J.: Alphaketoadipic aciduria: Degradation studies with fibroblasts. Clin. Chim. Acta,
58: 271 (1975).

26. Wilson, R. W., Wilson, C. M., Gates, S. C., and Higgins, J. V.: $\alpha$-Ketoadipic aciduria: A description of a new metabolic error in lysine-tryptophan degradation. Pediat. Res., 9: 522 (1975)

27. Wilson, R. W., Wilson, C. M., and Higgins, J. V.: Metabolism of $\alpha-$ aminoadipic acid and $\alpha$-ketoadipic acids. Clin. Chim. Acta, 69: 323 (1976).

28. Requests for reprints should be addressed to: Thorsten A. Fjellstedt, Ph.D.. National Institutes of Health, Landow Building, Room C718, Bethesda, MD 20014 (USA).

29. Received for publication March 23, 1977.

30. Accepted for publication July 21,1977 . 